Draft subnitled at Zikopoun Spring Semmar (i991)

\title{
PAC spectroscopy of electronic ceramics
}

DE92 014328

John A. Gardner. Ruiping Wang, and Rainer Schwenker

Department of Physics, Oregon Sluce Liniversity, Corvallis, Oregon 97331-6.50

USA

William E. Evenson

Department of Physics, Brigham Young University, Provo, Utain 84602 USA

Robert L. Rasera

Department of Physics, University of Maryland, Baltimore County, Catonsville, Maryland 21228 USA

James A. Sommers

Teledyne Wah Chang Albany, Inc., Albany, Oregon 97321 USA

\section{ABSTRACT}

Dilute indium dopants in cerium oxides and $\mathrm{YBa}_{2} \mathrm{Cu}_{3} \mathrm{O}_{x}$ have been studied by ${ }^{111} \mathrm{In} / \mathrm{Cd}$ Perturbed Angular Correlation (PAC) spectroscopy. By controlling oxygen vacancy concentration in the cerium oxides through doping or high-temperature vacuum annealing, we have found that indium always forms a defect complex unless the sample is doped to reduce greatly the oxygen vacancy concertration. Three different vacancy-associated complexes are found with concentraions that depend on doping and oxygen stoichiometry. Another defect complex occurs in samples having negligible vacancy concentration. At low temperatures, eridence is found of interaction with an electronic hole trapped by ${ }^{111} \mathrm{Cd}$ after the radioactive decay of the ${ }^{111}$ In parent. In $\mathrm{YBa}_{2} \mathrm{Cu}_{3} \mathrm{O}_{x}$ the indium substitutes preferentially at the $Y$ site but has measurable probability of substitution in at least one of the two copper sites. A symmetry change near $650{ }^{\circ} \mathrm{C}$ is consistent with the well-documented orthorhombic/terragonai iransition for samples in air or oxygen.

\section{INTRODUCTION}

Perturbed ingular Corrclation (P.AC) spectroscopy is an excellent technique for investigating a number of important properties of electronic ceramics. ${ }^{1-t}$ We have used ${ }^{111} \mathrm{In} / \mathrm{Cd}$ PAC to probe the structure and stability of indium donor-oxygen defect complexes in cerium oxide and have begun a study of microscopic structure of $\mathrm{YBa}_{2} \mathrm{Cu}_{3} \mathrm{O}_{\mathbf{x}}$. Cerium oxide has large ionic conductivity at high temperature and has g.eat potential for technological applications. $\mathrm{YBa}_{2} \mathrm{Cu}_{3} \mathrm{O}_{x}$ is a $90 \mathrm{~K}$ superconductor. 


\section{DISCLAIMER}

This report was prepared as an account of work sponsored by an agency of the United States Government. Neither the United States Government nor any agency thereof, nor any of their employees, makes any warranty, express or implied, or assumes any legal liability or responsibility for the accuracy, completeness, or usefulness of any information, apparatus, product, or process disclosed, or represents that its use would not infringe privately owned rights. Reference herein to any specific commercial product, process, or service by trade name, trademark, manufacturer, or otherwise does not necessarily constitute or imply its endorsement, recommendation, or favoring by the United States Government or any agency thereof. The views and opinions of authors expressed herein do not necessarily state or reflect those of the United States Government or any agency thereof. 
$\mathrm{CeO}_{2}$ is the stable oxide of cerium in air. The oxygen concentration can be decreased by annealing in a reduced oxygen pressure at high temperature. Such material has a substantial electronic and ionic conductivity. ${ }^{-3}$ Ceria is uften doped with trivalent (usually rare-earth) or divalent ( $\mathrm{Ca} . \mathrm{Mg}$ ) cations. The cationic charge diference is compensated largejy bxygen vacancies, so such materiais are hightemperature ionic conductors but have small electronic conductivity. ${ }^{6-8}$ The interaction of dopants with oxygen defects is an important topic. Our work probes complexes of (trivalent) indium dopants with oxygen defects.

$\mathrm{CeO}_{2}$ has the cubic fluorite structure, so the electric field gradient (efg) at the $\mathrm{Ce}$ position in a perfect crystal will be zero. If the ${ }^{111} \mathrm{Cd}$ nucleus is substituted at a $\mathrm{Ce}$ site with no nearby defects, then the ${ }^{111} \mathrm{Cd}$ PAC spectrum should be unperturbed. We have investigated a number of ceria samples in which the oxygen vacancy concentration is controlled by doping or high-temperature annealing. Measurements have been made on samples held at temperatures ranging from $10 \mathrm{~K}$ to $1400 \mathrm{~K}$, and only near the highest temperatures in this range is the PAC spectrum unperturbed. At lower temperatures, we find a variety of interactions and can identify at least four well-defined defect-associated sites. At temperatures below $500 \mathrm{~K}$. we always find evidence for "aftereffects" of the "In electron capture decay.

${ }^{111} \mathrm{In} / \mathrm{Cd} \mathrm{PAC}$ in $\mathrm{YBa}_{2} \mathrm{Cu}_{3} \mathrm{O}_{x}$ has not been a straightforward experimental investigation. $A$ number of groups have attempted $\mathrm{PAC}$ measurements ${ }^{3-1.4}$ and have obtained non-reproducible spectra whose interpretation has been controversial. ${ }^{15}$ Although the indium solubility in $\mathrm{YBa}_{2} \mathrm{Cu}_{3} \mathrm{O}_{\mathbf{x}}$ is approximately $3 \%$ per formula weight. ${ }^{16}$ it has proven extraordinarily difficult to synthesize samples in which the

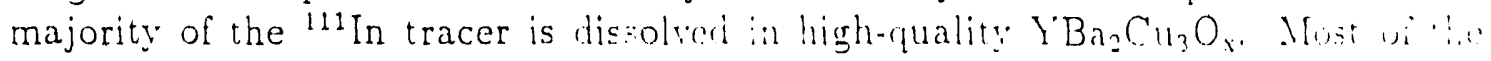
common synthesis methods produce material in which the majority of the ${ }^{111}$ In is dissolved in phases other than $\mathrm{YBa}_{2} \mathrm{Cu}_{3} \mathrm{O}_{\mathrm{x}}$. We have recently developed a reproducible method for making samples in which the majority of the "In is dissoiven in $\mathrm{YBa}_{2} \mathrm{Cu}_{3} \mathrm{O}_{\mathrm{x}}$. We find that indium substitutes predominantly at the l' site but also has a substantial probability of substitution in at least one of the copper sires. We have vbserved the orthorhombic/tetragonal phase transition in samples hearei in flowing oxygen and report preliminary data here.

\section{RESULTS OF $\mathrm{CeO}_{2}$ EXPERIMENTS}

We have performed measurements over a wide temperature range on pure and lightly-doped $\mathrm{CeO}_{2}$ samples containing trace levels (of order $10^{-9}$ per formula weight) of ${ }^{111}$ In. Samples were made by ammonium precipitation from cerium ammonium nitrate solutions of the desired cation stoichiometry. "

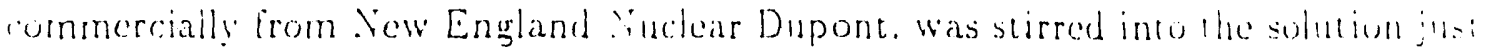
prior to precipitation. Samples were calcined at $1500^{\circ} \mathrm{C}$ or higher for $b$ hours prior to measurement. This preparation method resulted in oxide grains of order $10 \mathrm{mi}$ crons diameter. Samples calcined below $1200^{\circ} \mathrm{C}$ had much smaller grains and a significant probability that the ${ }^{111}$ In was not dissolved in the bulk. 


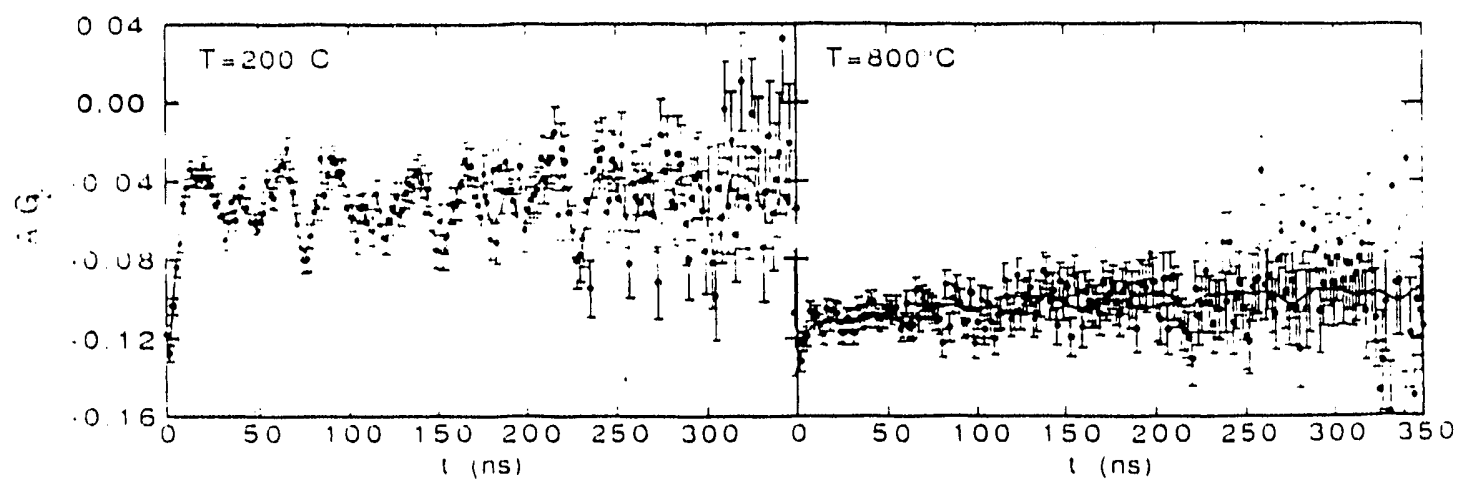

Figure 1: ${ }^{111} \mathrm{Cd}$ PAC expurimental $A_{2} G_{2}$ spectra for cerium oxide doped with 500 ppm $\mathrm{Nb}$ per formula weight.

The PAC measurements were carried out using a 4-detector spectrometer with $\mathrm{BaF}_{2}$ scintillator detectors. The apparatus is similar to one described previously. ${ }^{17}$

Figure 1 shows the experimental $A_{2} G_{2}(t)$ PAC spectra for a typical ceria sample doped with $\mathrm{Nb}$, a pentavalent cation introduced to reduce the oxygen vacancy concentration to negligible levels. Below $175 \mathrm{~K}$. the spectra are typical of an "aitereffects" interaction. ${ }^{18} G_{2}(t)$ decays rapidly with time due to interaction between the $\mathrm{Cd}$ nucleus and an electronic hole metastably trapped after the electron capture decay of the ${ }^{111}$ In parent. This interaction is not understood in detail, and we model it by a single exponential. The model is heuristic and fits the data well but not perfectly. In ail cascs. the experimental Ga $(t)$ does not decay exactly to zerc. although the "hard core" remaining at long time is small and may be an experimental artifact.

We have made only cursory measurements below room temperature. so this region remains to be explored in luture work. At and above room temperature. We find that a small fraction of the Cal nuclei are subject to a well-defined interaction with a large. asymmetric electric field gradient (efg). The relative fraction of such sites decreases with temperature and becomes negligible at temperatures of order $1000 \mathrm{~K}$. The interaction frequencics are reproducible from sample to sample, but the relative fraction is not. We do not presently understand how this static interaction arises. The PAC spectrum due to the remaining ${ }^{111} \mathrm{Cd}$ nuclei can be well fitted by an exponential and a constant. The fractional weights of the exponential. constant, and static interaction contributions to the spectrum are shown in Fig. 2. The damping rate of the exponential is shown in Fig. 3(a).

It is reasonable to assume that the exponential and constant terms arise from nuclei in substitutional cerium positions in which the escape time for the trappen "altereffects" hole is of urder nanuseconds. It is straightforward to shuw."st that in such a case $G_{2}(t)$ is given by:

$$
G_{2}(t)=\frac{r}{r+\lambda_{a}}+\frac{\lambda_{a}}{r+\lambda_{a}} e^{-\left(\lambda_{a}+r\right) t}
$$

provided $G_{2}(t)$ is well-approximated by a single exponential when the hole escape 


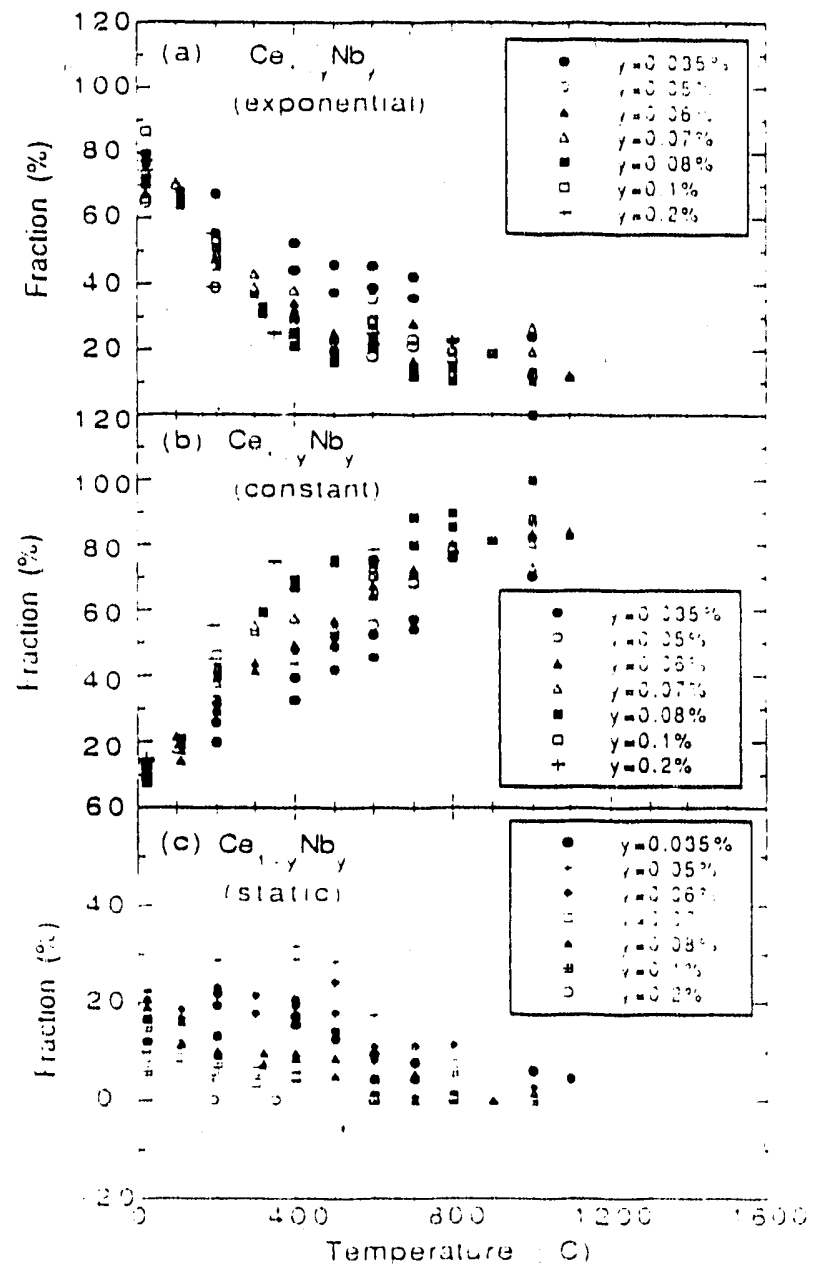

Figure 2: Fractions of (a) exponential, (b) constant, and (c) static interaction models used to fit the spectra of $\mathrm{Nb}$-doped ceria at elevated temperatures. 


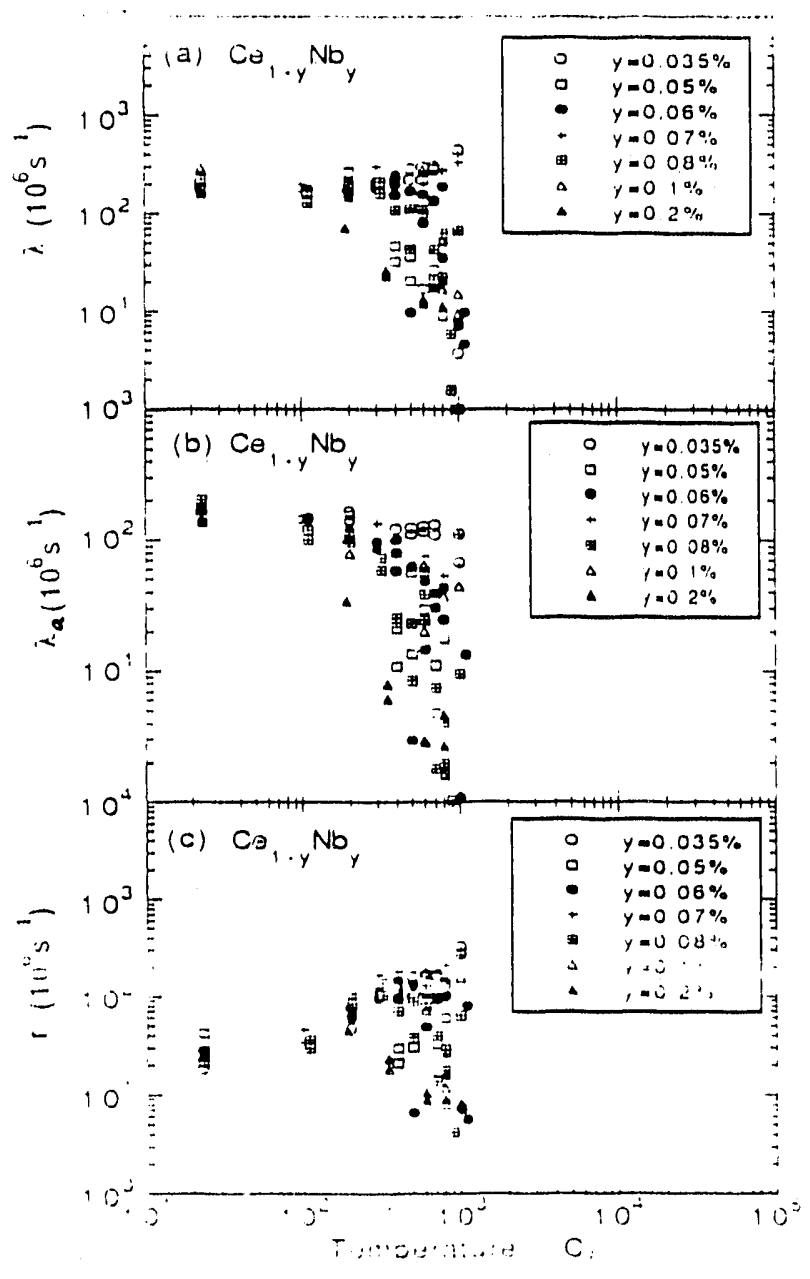

Figure 3: (a) Damping rate of the exponential model for Nb-doped ccria. (b) Exponential decay rate $\lambda_{a}$ for ${ }^{111} \mathrm{Cd}$ PAC spectrum in presence of trapped "aftereffects" hole, and (c) escape rate $r$ of the hole. Within this model $\lambda_{a}+r=\lambda$, where $\lambda_{a}$ and $r$ are defined by Eq. 1 in text. 


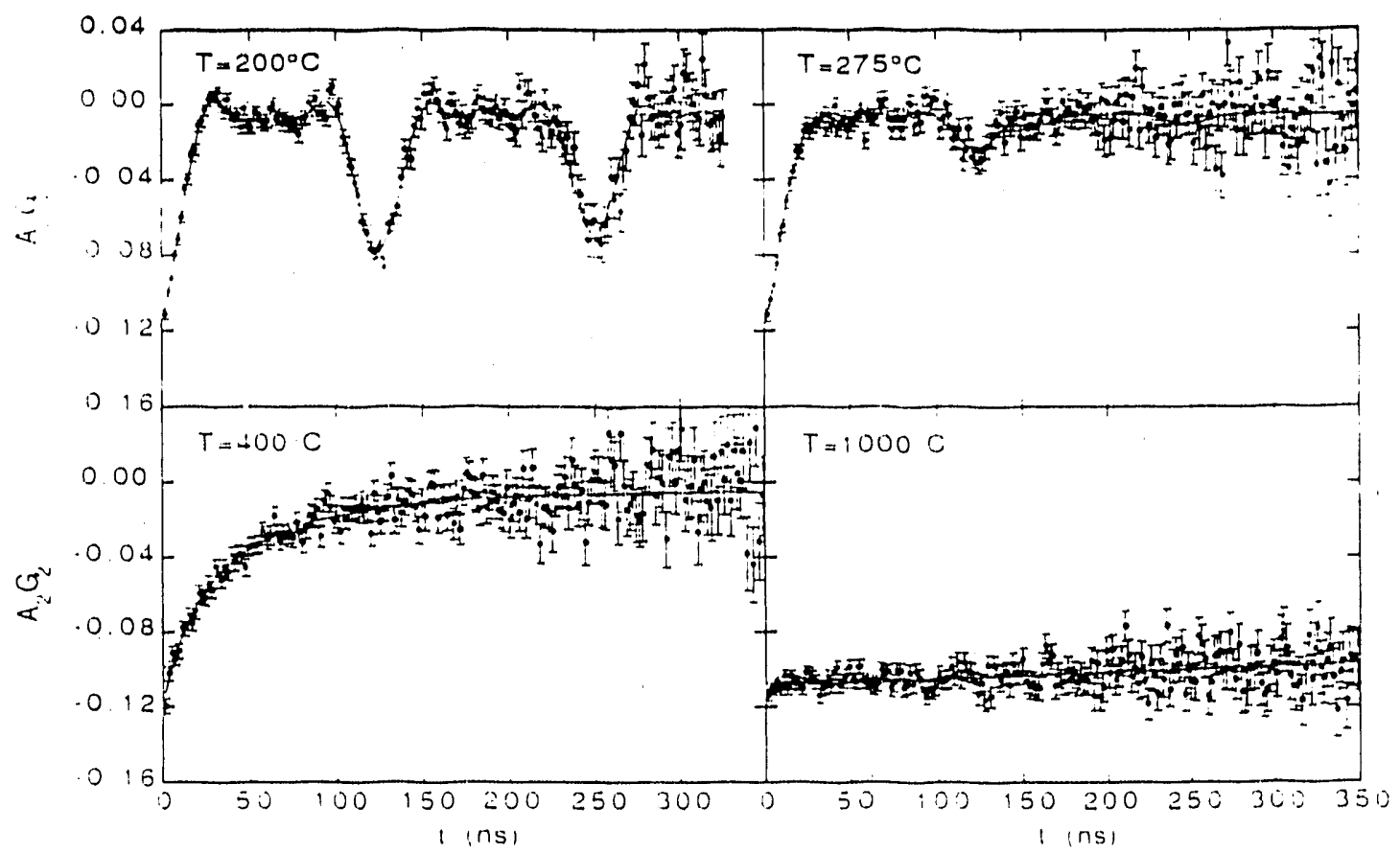

Figure 4: ${ }^{111} \mathrm{Cd}$ PAC experimental $A_{2} G_{2}$ spectra for undoped cerium oxide.

rate $r$ becomes very small. The rates $\lambda_{a}$ and $r$ are shown in Figs. 3(b) and (c).

Spectra qualitatively similar to those of Fig. 1 are found for samples containing more than $300 \mathrm{ppm} \mathrm{Nb}$. P.AC spectra from undoped ceria are shown in Fig. t. The spectrum at low temperature has a substantial aftereffects behavior. but aimost. half the ${ }^{111} \mathrm{Cd}$ nuclei are subject to a static interaction with a moderate-magnitude axially-symmetric efg. At $200^{\circ} \mathrm{C}$ afterelfects are negligible, and the fraction of $\mathrm{C}$.if nuclei subject to the siatic interaction is $100 \%$ within experimental uncertainty. Ne speculate that the ${ }^{111}$ In parent is associated with a strongly-bound oxtgen vacanc: comples and that the probabiity of trapping a hole after ${ }^{111}$ In decn! is appros. imately 50\%. Thus, at low temperature, approximately $50 \%$ of the spectrum is affected by the aftereffect interaction, but above $200^{\circ} \mathrm{C}$ the hole escape rate is fast enough that its interaction with the ${ }^{111} \mathrm{Cd}$ nucleus has negligible effect on the $\mathrm{P} . \mathrm{AC}$ spectrum.

Figure 5 shows the Fourier transform of the $200{ }^{\circ} \mathrm{C} A_{2} G_{2}(t)$ spectrum. This figure shows a frequency triplet with frequencies having ratios $1: 2: 3$, the signature of a quadrupolar interaction with an axially-symmetric efg. At higher temperatures, the frequencies broaden, and the $A_{2} G_{2}(t)$ spectrum shows clearly that the efg is no

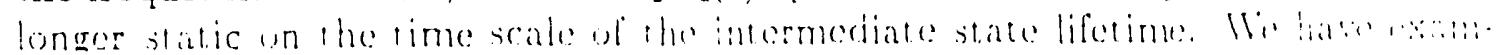
ined two possibilities for the time-dependence. One possibility is that the oxygen vacancy escapes at high temperature. The second possibility is that the complex remains bound but that its symmetry axis direction changes due to thermal excitation. Detailed analysis, to be described in a later paper, clearly demonstrates that 


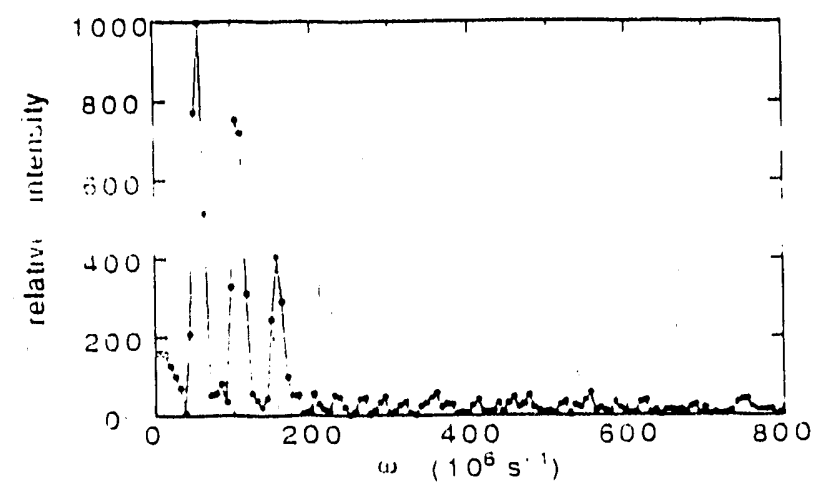

Figure 5: Fourier transform of $200^{\circ} \mathrm{C}$ spectrum from Fig. 4.

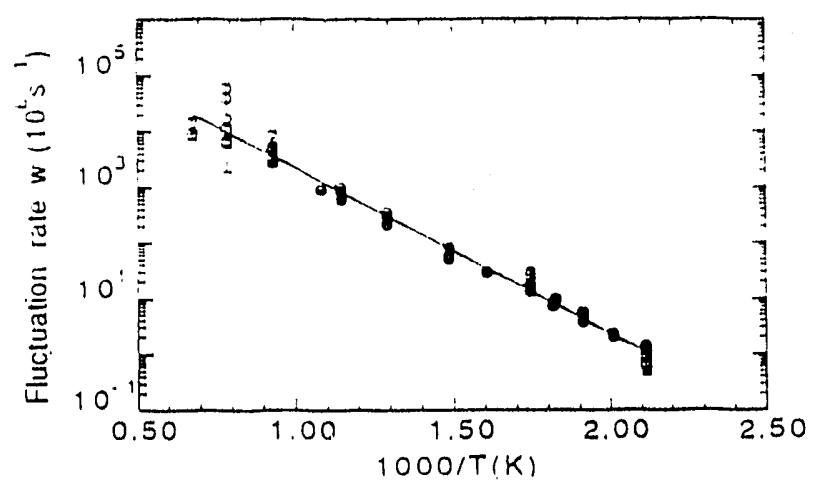

Figure 6: Single fitting parameter w vs. 1/T. The fitting model is described in Ref. 21.

the experimental data disagree qualitatively with the first possibility but can be: quantitatively explained by the second.

The random axis-reorientation hypothesis can be lescribed accurately by a morici developed by Evenson et al. ${ }^{21.22}$ W: assume that the efg tensor remains constant

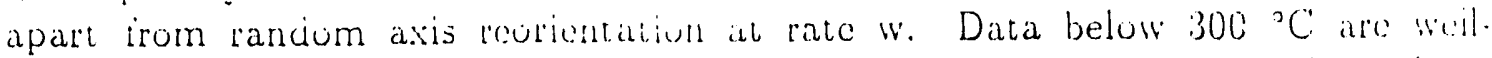
represented by the "slow" limit ( $w / \omega_{Q}$ small) of the model, whereas data above $100{ }^{\circ} \mathrm{C}$ are accurately described hy the "fast" limit. The single fitting parameter $w$ is shown vs. 1/T in Fig. 6. The activation energy for the axis-reorientation process is $0.6(0.2) \mathrm{eV}$. Figure 7 shows the (a) fractional weight, (b) the damping rate of the exponential decay used to approximate the "aftereffects" spectrum, and (c) the interaction frequencies $\omega_{1}$ and 2 .

In Fig. o(a) we show the P.IC spectrum at $23^{\circ} \mathrm{C}$ lor an undoped ceria sampic that had been annealed for 30 minutes in a mechanical pump vacuum at $900^{\circ} \mathrm{C}$ and in $8(\mathrm{~b})$ for a sample annealed at $1000^{\circ} \mathrm{C}$. After annealing, these samples were sealed in order tc keep the oxygen vacancy concentration constant. In addition to the site seen in undoped ceria (referred to as site $A$ ), two additional sites ( $B$ and $C$ ) are 


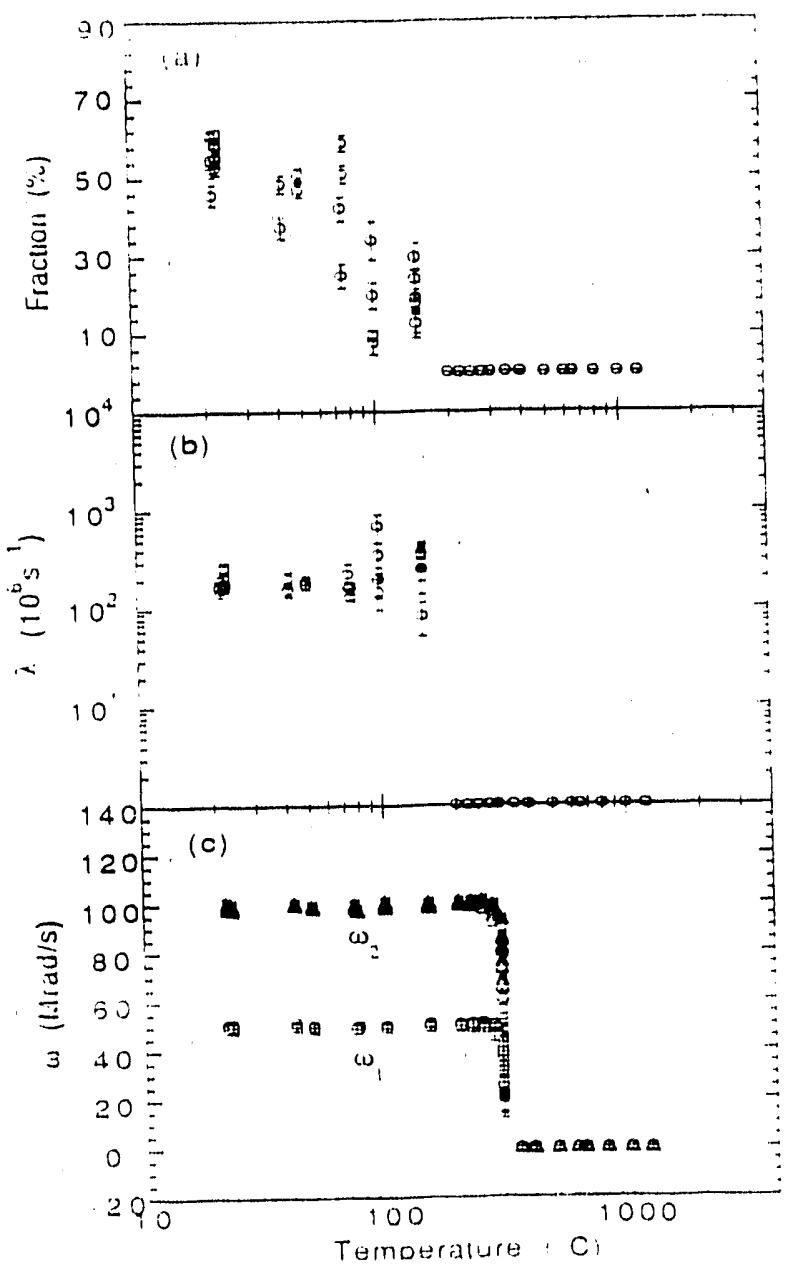

Figure 7 : (a) Fraction and (b) damping rate of exponential interaction used to fit undoped ceria spectra. (c) Interaction frequencies for the A-site interaction. The quadrupole frequency $\omega_{Q}=300 \times 10^{\circ}$ is obtained from fitting spectra in the static region below $300^{\circ} \mathrm{C}$ and is held fixed at that value for higher temperatures. 


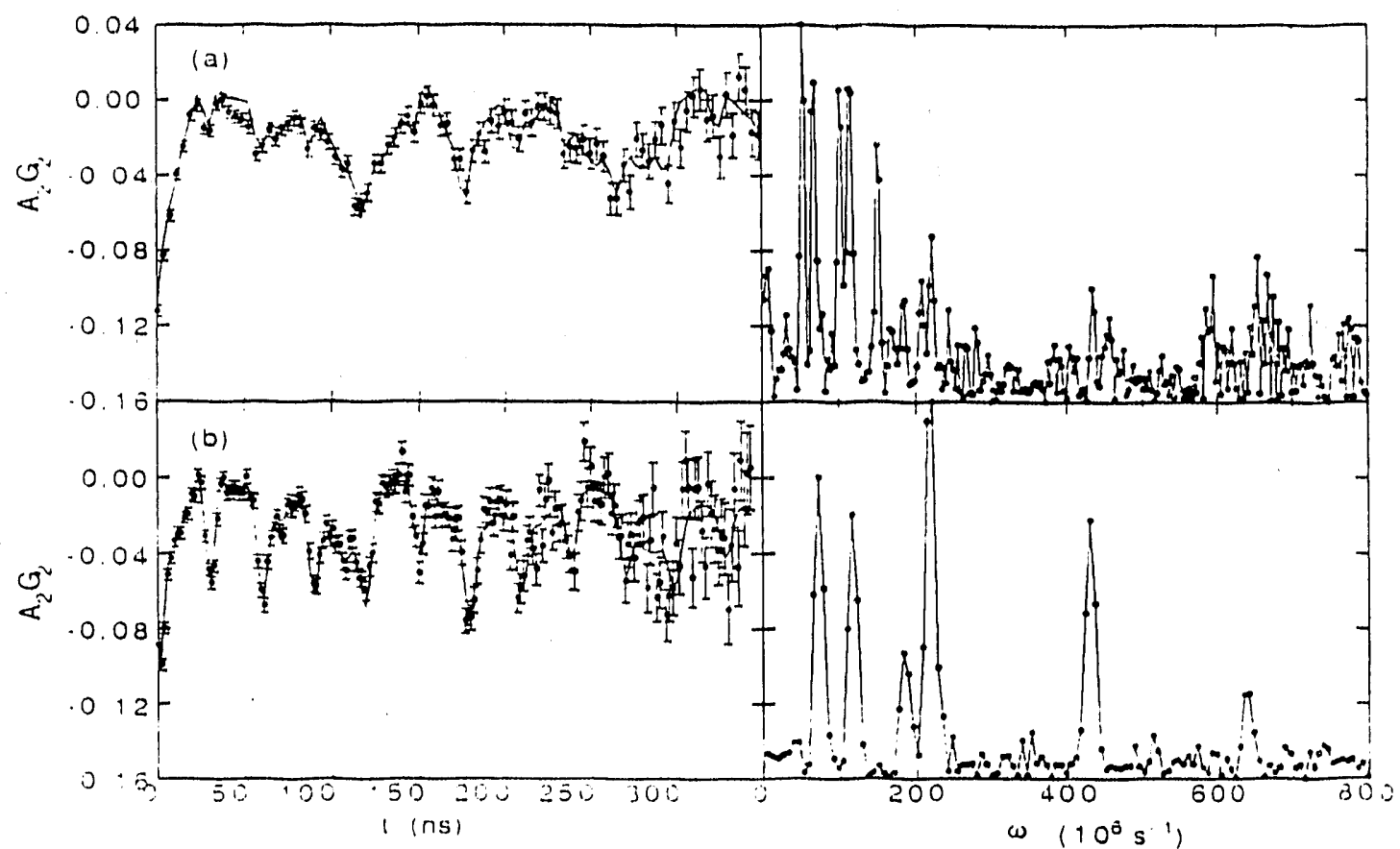

Figure $s:{ }^{111} \mathrm{Cd}$ PAC experimental $A_{2} G_{2}$ spectra and Fourier transforms for undoperd

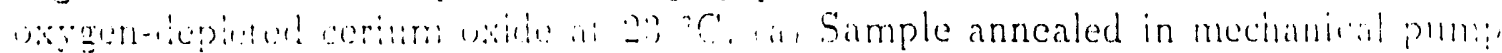
vacuum at $900^{\circ} \mathrm{C}$ and (b) at 100()$^{\circ} \mathrm{C}$. 
found. We tentatively attribute sites $B$ and $C$ to the presence of additional oxygen vacancies bound to the original site-A complex. The microscopic structure giving rise to these spectra has not been established unambiguously. We have speculated that site $A$ has a missing oxyen atom next to the indium atom and that the indium atom of site $C$ has two neighboring oxygen vacancies torming a Bevan cluster."

We find that PAC spectra are not strongly affected by minor contamination by rare-earth impurities that are commonly found in cerium oxides. We have used both a very high purity stock solution (cation impurities fewer than $20 \mathrm{ppm}$ ) and a commercial solution containing approximately $300 \mathrm{ppm}$ rare-earth contaminants. No differences were found. It is interesting to note that approximately $300 \mathrm{ppm} \mathrm{Nb}$ is required to change the spectra from those of Fig. \& to those of Fig. 1.

We have also carried out measurements of PAC spectra on samples doped with as much as $1 \%$ per formula weight of yttrium or indium. Samples doped with more than $0.4 \%$ yttrium have measureable contributions from sites of types $\mathrm{B}$ and $\mathrm{C}$. All In-doped samples have spectra identical to those of pure ceria. These findings imply that indium doe not introduce free oxygen vacancies and should therefore not yield materials with large ionic conductivity. To our knowledge, the ionic conductivity of indium-doped ceria has not been measured.

\section{RESULTS OF $\mathrm{YBa}_{2} \mathrm{Cu}_{3} \mathrm{O}_{\mathbf{x}}$ EXPERIMENTS}

We have tried a variety of sample-making techniques. Diffusion of indium into previously-synthesized $\mathrm{YBa}_{2} \mathrm{Cu}_{3} \mathrm{O}_{\mathrm{x}}$ was unsuccessful. The indium was apparently largely dissolved in non-representative surface lavers or intergranular phases. We found very good spectra and extremely sharp Meissner Hux exclusion for samples made by an evaporation method. ${ }^{13,14}$ Unfortunately, little indium was dissolved in the majority phase. When samples were synthesized in flowing air or oxygen. most indium dissolved in $\mathrm{Y}_{2} \mathrm{BaCuO}_{5}$, although only a few percent of this phase was present in our samples. When samples were prepared in a restricted air flow. the indium dissolved preferentially in some other second phase whose composition we have not tried to identify. The P.\C spectrum in this latter case ${ }^{13}$ is characterized by.

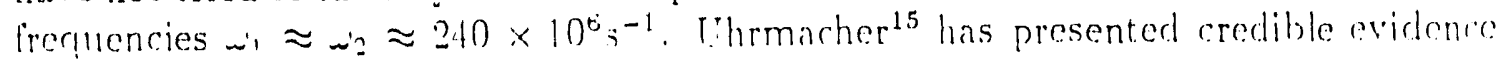
that this particular PAC signal arises trom indium substituted in an yttrium-copper oxide phase.

We have achieved better success using a sol-gel sample preparaticn method. An EDTA solution containing $\mathrm{Y}, \mathrm{Ba}$, and $\mathrm{Cu}$ in ratio 1:2:3 was prepared from high purity metal nitrates. After stirring in the appropriate amount of ${ }^{111}$ In solution, the mixture was dehydrated and converted to oxides in a ceramic casserole on a huplate. Samples were symhesizer under at ariety of conditions at temperatures ranging from 900 to $940^{\circ} \mathrm{C}$ for times of 15 minutes to 12 hours. Some were airquencheid. Others were cooled slowly over a number of hours before being placed in the PAC spectrometer furnace. In all cases, most of the indium was dissolved in the majority $\mathrm{YBa}_{2} \mathrm{Cu}_{3} \mathrm{O}_{x}$ phase, but no synthesis condition was found that resulted in dissolving $100 \%$ of the indium tracer. 
In Fig. 9 we show ${ }^{111} \mathrm{Cd}$ PAC spectra for such samples at four different temperatures. These data were taken with a spectrometer using four $\mathrm{NaI}(\mathrm{Tl})$ scintillator detectors but otherwise similar to the apparatus used for the ceria experiments. In Fig. 10 we show the frequencies and relative fractions of two sites that we identify. tentatively as indium substituted at the $\mathrm{Y}$ site and at the $\mathrm{Cu}-\mathrm{l}$ site in $\mathrm{YBa}_{2} \mathrm{Cu}_{3} \mathrm{O}_{x}$. Although the exact site identificaion is not certain, it is unambiguously clear that the two sites are associated with $\mathrm{YBa}_{2} \mathrm{Cu}_{3} \mathrm{O}_{\mathrm{x}}$ and not some second phase. We base this assertion on the behavior at the melting transition. At a temperature near $1000^{\circ} \mathrm{C}$ in air and approximately $1030{ }^{\circ} \mathrm{C}$ in flowing oxygen, $\mathrm{YBa}_{2} \mathrm{Cu}_{3} \mathrm{O}_{\mathrm{x}}$ decomposes into $\mathrm{Y}_{2} \mathrm{BaCuO}_{5}$ and a melt. As seen in Fig. 9, the PAC spectrum changes substantially above this temperature, with the two $\mathrm{YBa}_{2} \mathrm{Cu}_{3} \mathrm{O}_{\mathbf{x}}$ sites disappearing and the $\mathrm{Y}_{2} \mathrm{BaCuO}_{5}$ site becoming substantially stronger. We have also observed that the $240 \mathrm{Mrad}$ signal described above persists well above the $\mathrm{YBa}_{2} \mathrm{Cu}_{3} \mathrm{O}_{\mathrm{x}}$ decomposition temperature. In such high temperature spectra there is also a substantial contribution from indium atoms dissolved in the melt where their average efg is zero and their contribution to $G_{2}(t)$ is unperturbed.

The frequencies and relative fractions of the two $\mathrm{YBa}_{2} \mathrm{Cl}_{3} \mathrm{O}_{\mathbf{x}}$ sites shown in Fig. 10 both change substantially in the temperature range between 600 and $750^{\circ} \mathrm{C}$ where the structure is known to change from orthorhombic to tetragonal. As expected. the site symmetries change from slightly asymmetric at low temperature to symmetric at high temperature. The transition region is still under investigation.

An interesting feature shown in Fig. 10 is that the site occupation probabilities change substantially above $900^{\circ} \mathrm{C}$. A third site having a very large $\omega_{1}$ of order $450 \times 10^{6} \mathrm{~s}^{-1}$ is found near $1000^{\circ} \mathrm{C}$. We suspect that this may be the Cu-2 site, but further measurements on a higher-resolution spectrometer are required to test this hypothesis.

\section{ACKNOWVEDGEMENTS}

We thank Mr. John Griffith and Mr. Randy Lundquist for technical assistance in data acquisition and computer analysis. We also thank Mr. Mark Preddy for his typesetting offorts. The rescarch on cerium oxide was sponsored in part by the: US Department of Energy contract DE-FG06-85ER45191. The work on Y' $\mathrm{Ba}_{2} \mathrm{Cu}_{3} \mathrm{O}_{x}$ was supported in part by the US National Science Foundation under contract MSMI8717809 . 


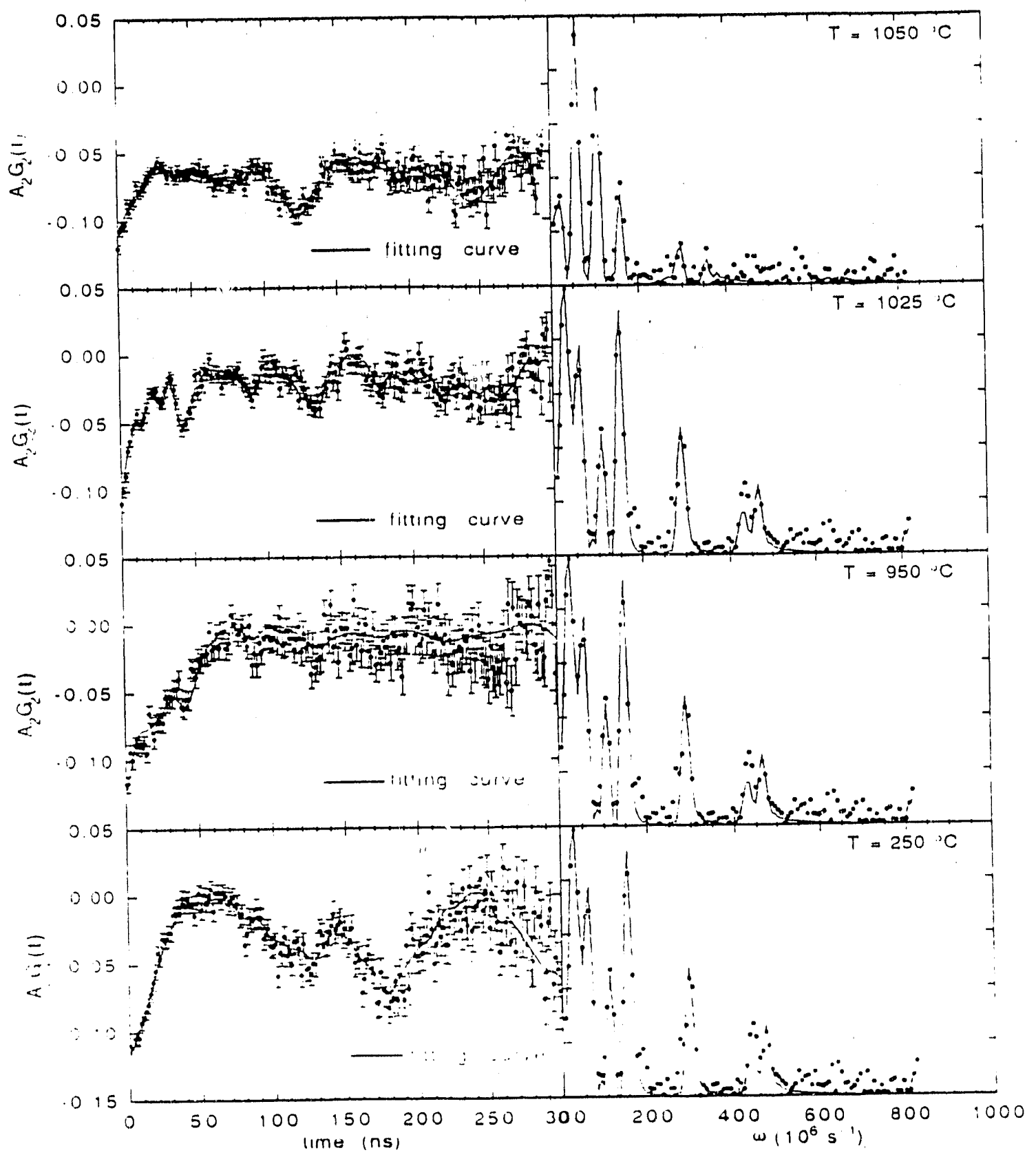

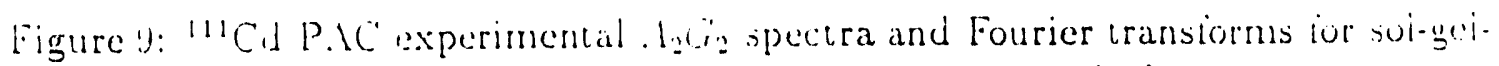
synthesized $\mathrm{YBa}_{2} \mathrm{Cu}_{3} \mathrm{O}_{x}$ samples held in fowing oxygen. At the lowesi temperature, the material is in the orthorhombic phase, at the two higher temperatures, it is tetragonal. The highest temperature is above the decomposition temperature. 

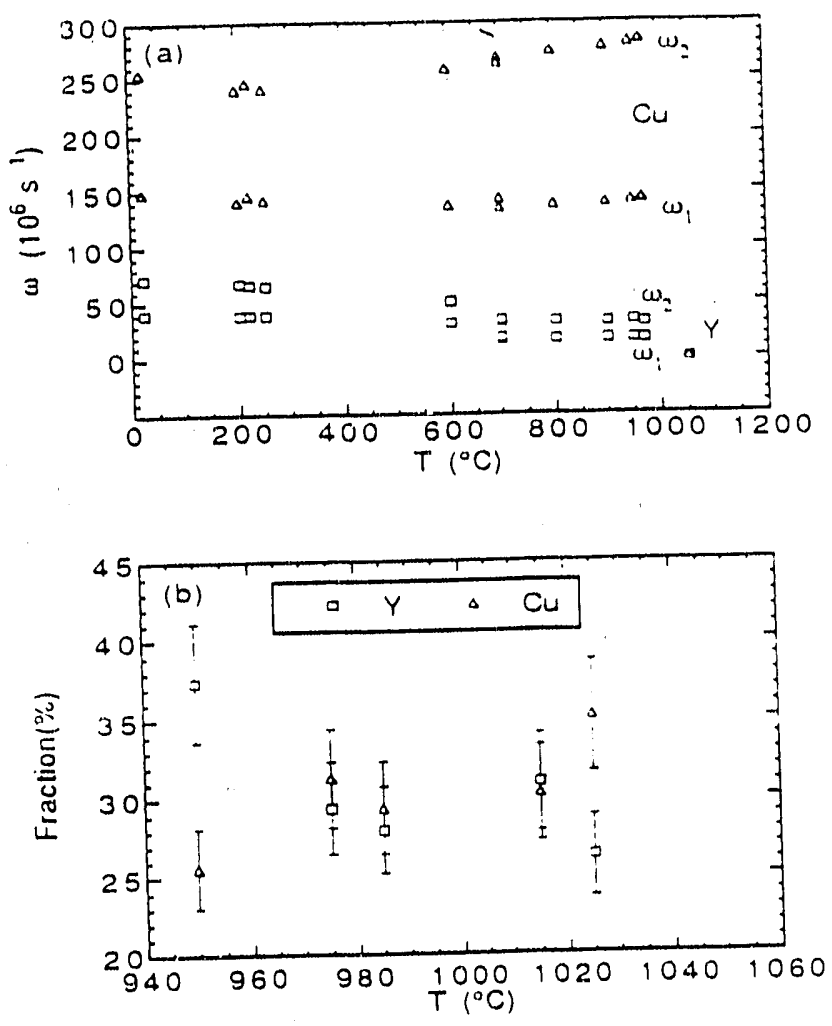

Figu're 10: (a) Frequencies of sites from a representative $\mathrm{YBa}_{2} \mathrm{Cu}_{3} \mathrm{O}_{\mathbf{x}}$ sample. Sites labeled $Y$ and $\mathrm{Cu}$ are tentatively identified as the $\mathrm{Y}$ and $\mathrm{Cu}-1$ substitution positions in $\mathrm{YBa}_{2} \mathrm{Cu}_{3} \mathrm{O}_{\mathbf{x}}$. Each site is assumed to have a static efg, so spectra near the orthorbombic transition temperature were not properly fitted. (b) Fraction of the $\mathrm{Y}$ site and $\mathrm{Cu}-1$ site in a sample for which the $\mathrm{Y} 211$ site fraction has a value of $20 \%$. 

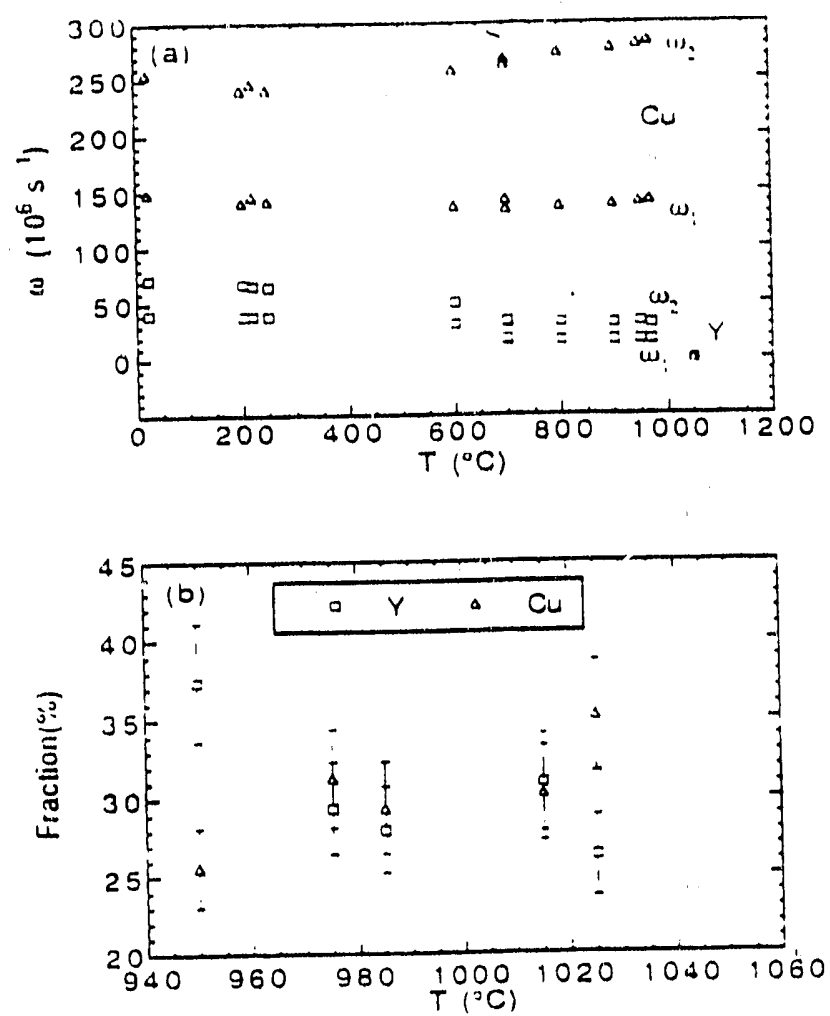

Figure 10: (a) Frequencies of sites from a representative $\mathrm{YBa}_{2} \mathrm{Cu}_{3} \mathrm{O}_{x}$ sample. Sites labeled $Y$ and $C u$ are tentatively identified as the $Y$ and $C u-1$ substitution positions in $\mathrm{YBa}_{2} \mathrm{Cu}_{3} \mathrm{O}_{x}$. Each site is assumed to have a static efg, so spectra near the orthorhombic transition temperature were not properly fitted. (b) Fraction of the $\mathrm{Y}$ site and $\mathrm{Cu}-1$ site in a sample for which the $\mathrm{Y} 211$ site fraction has a value of $20 \%$. 


\section{References}

(1) H. Jaeger, John A. Gardner, John C. Haygarth, and R. L. Rasera, J. Am. Ceram. Soc. $\underline{69}, 458$ (1986).

[2] J. A. Gardner, H. Jaeger, H. T. Su, and J. C. Haygarth, Physica B 1.50, 223 (1988).

[3] H.-T. Su, R. P. Wang, H. Fuchs, J. A. Gardner, W. E. Evenson, and J. A. Sommers, J. Am. Ceram. Soc. 73, 3215 (1990).

[4] R. P. Wang, J. A. Gardner, W. E. Evenson, and J. A. Sommers, paper presented at the 1991 annual meeting of the American Ceramics Society, and to be published in proceedings of the symposium on defects in oxides.

[5] H. L. Tuller and A. S. Nowick, J. Phys. Chem. Solids, 38, 859 (1977).

[6] R. Gerhardt-Anderson and A. S. Nowick, Transport in Nonstoichiometric Compounds, edited by G. Simkovich, (Plenum Press, New York, 1985).

[i] D. Y. Wang and A. S. Nowick. J. Phys. Chem. Solids, IT, 639 (1983).

(8) R. Gerhardt, W.-K. Lee, and A. S. Nowick, J. Phys. Chem. Solids 48,563 (1987).

[9] M. Uhrmacher and A. Bartos, paper presented at the Eighth International Conference on Hyperfine Interactions, Prague, 1989, to be published in conference proceedings issue of Hyperfine Interactions.

(10] H. Plank, F. Meyer, and V. Witthuhn, Phys. Lett. A133, 451 (1988).

(11) P. Singh. M. N. Nyayate. S. H. Devare. and H. G. Devare. Phys. Rev. B 3:2, 2308 (1989).

'2! C. L. Catchen. M. Blaszkiewicz. A. J. Baratta and WV. Huchner. Phys. Rur. B 运, $2524(1900)$.

(13) H. T. Su, A. G. McKale, S. S. Kao, L. L. Peng, W. H. Warnes, John A. Gardner, and J. A. Sommers, Ceramic Superconductors II, (American Ceramic Society, Westerville, Ohio, 1988).

11.t J. A. Gardner. H. T. Su, A. G. McKale. S. S. Kao, T. L. Peng. IV. H. Marnme. J. A. Sommers. K. Ahreya. H. Franzen, and S.-J. Kïm. Phys. Rev. B LE, 113i (1988).

[15] M. Uhrmacher and A. Bartos, Hyperfine Interactions 61, 1073 (1990). 
(16) G. Weidlich, M. Goelz, R. P. Wang, W. E. Evenson, J. A. Gardner, D. A. Keszler, J. A. Sommers, and J. E. Ostenson, J. Mater. Res. 6, 146 (1991).

[17] H. Jaeger, J. A. Gardner, H. T. Su, and R. L. Rasera. Review of Scientific Instruments. 20. 169.t (198T).

[18] A. G. Bibiloni, C. P. Massolo, J. Desimoni, L. A. Mendoza-Zélis, F. H. Sánchez, A. F. Pasquevich, L. Darnonte, and A. R. López-Garcia, Phys. Rev. B 32, 2393 (1985).

[19] A. G. Bibiloni, J. Desimoni, C. P. Massolo, L. A. Mendoza-Zélis, A. F. Pasquevich, F. H. Sánchez, and A. R. López-Garcia, Phys. Rev. B 29, 1109 (1984).

[20] R. P. Wang, PhD thesis, Oregon State University, 1991, (unpublished).

[21] W. E. Evenson, A. G. McKale, H. T. Su, and J. A. Gardner, Hyperfine Interactions $61,1379(1990)$.

[22] W. E. Evenson, J. A. Gardner, R. P. Wang, H.-T. Su, and A. G. McKale, submitted to Hyperfine Interactions, July, 1990.

[23] D. J. M. Bevan and J. Kordis, J. Inorg. Nucl. Chem. 26, 1509 (1954). 

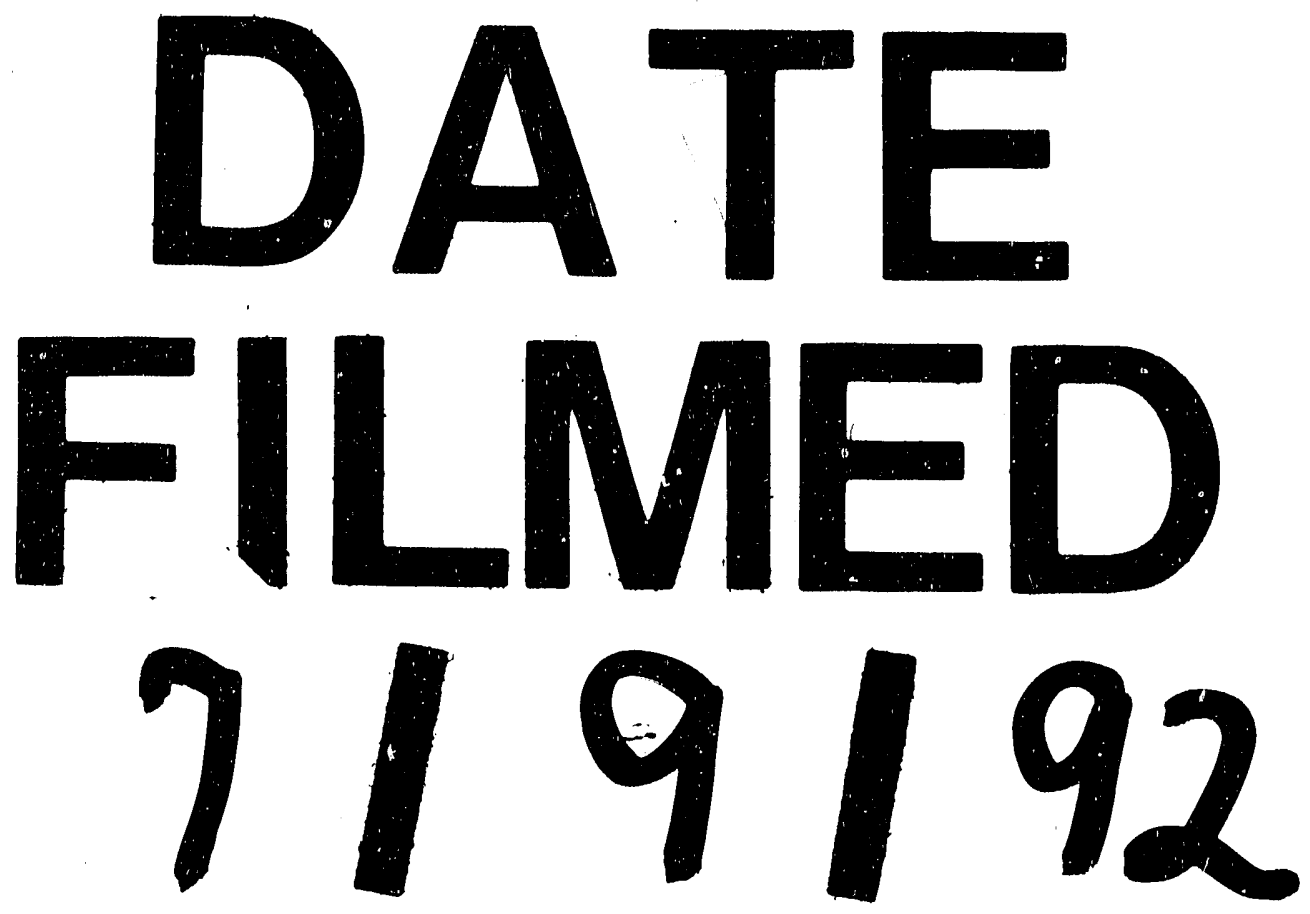
